\title{
IMPLEMENTASI PEMBELAJARAN PROBLEM BASED LEARNING BERBASIS NILAI PANCASILA DALAM MENGHADAPI REVOLUSI INDUSTRI 4.0 BAGI SISWA KELAS VIII DI SMP NEGERI 1 KARTASURA TAHUN PELAJARAN 2018-2019
}

\author{
Suyahman \\ Dosen Progdi PPKn \\ FKIP Univet Bantara Sukoharjo \\ Email: suyahman.suyahman@yahoo.com
}

\begin{abstract}
ABSTRAK
Penelitian ini bertujuan mendeskripsikan pembelajaran problem based learning berbasis nilai pancasila dalam menghadapi revolusi industri 4.0 bagi siswa Kelas VIII di SMP Negeri 1 Kartasura tahun Pelajaran 2018-2019. Penelitian ini adalah penelitian deskriptif kualitatif. Subjek penelitiannya: guru PPKn dan siswa kelas VIII di SMP Negeri 1 Kartasura, dan objeknya adalah pembelajaran inovatif berbasis nilai pancasila dan refolusi industri 4.0. Metode pengumpulan data menggunakan: observasi, wawancara dan dokumentasi. Validitas data dilakukan dengan trianggulasi sumber dan metode. Teknik analisis data dilakukan dengan teknik analisis kualitatif terdiri dari 4 tahap yaitu: pengumpulan data, reduksi data, display data dan verifikasi data. Hasil penelitian: berdasarkan hasil pengamatan dilapangan yang dilakukan dari tanggal 14-20 maret 2019 ditemukan hal-hal sebagai berikut: dalam pembelajaran terlihat siswa aktif, siswa berani mengemukakan pendapat, guru neghargai pendapat siswa yang berbeda, guru bersikap demokratis, guru memberi kesempatan siswa untuk bertanya, guru memposisikan diri hanya sebagai fasilitator, guru mengakui potnsi yang dimiliki siswa berbeda, guru tidak hanya menekankan pada aspek pengetahuan akan tetapi lebih mengedepankan aspek sikap, guru memberikan contoh-contoh konkrit sikap positif yang harus dimiliki siswa untuk menghadapi revolusi industri 4.0, guru menginstruksikan pada siswa untuk tidak menolak globalisasi akan tetapi menerima dengan filter nilai-nilai pancasila. Simpulannya bahwa dengan penerapan pembelajaran problem based learning yang berbasis nilai-nilai pancasila dapat mendaya daya dukung siswa dalam menghadapi revolusi industri 4.0 bagi siswa kelas VIIIsiswa kelas VII di SMP Negeri 1 Kartasura tahun Pelajaran 2018-2019.
\end{abstract}

Kata-kata Kunci: Pembelajaran Problem Based Learning Berbasis Nilai Pancasila dan Refolusi Industri 4.0 


\begin{abstract}
Abstract. This study aims to describe the learning of Pancasila value-based problem based learning in the face of the 4.0 industrial revolution for Class VIII students in Kartasura 1 Public Middle School 2018-2019 academic year. This research is a qualitative descriptive study. The research subjects: PPKn teachers and VIII grade students at SMP Negeri 1 Kartasura, and the object is innovative learning based on Pancasila values and industrial reflux 4.0. The method of data collection uses: observation, interviews and documentation. Data validity is done by triangulation of sources and methods. The data analysis technique is done by qualitative analysis techniques consisting of 4 stages, namely: data collection, data reduction, data display and data verification. The results of the study: based on field observations conducted from March 14-20 2019 found the following: in learning seen active students, students dared to express opinions, teachers negated the opinions of different students, teachers behaved democratically, teachers gave students the opportunity to ask, the teacher positions himself only as a facilitator, the teacher recognizes the potential that students have is different, the teacher does not only emphasize the aspects of knowledge but put forward the aspects of attitude, the teacher provides concrete examples of positive attitudes students must have to face the industrial revolution 4.0, teacher instruct students not to reject globalization but accept with a filter the values of the Pancasila. The conclusion is that the application of problem-based learning based on Pancasila values can power the carrying capacity of students in facing the 4.0 industrial revolution for VII grade students of class VII in Kartasura 1 Public Middle School 2018-2019 academic year.
\end{abstract}

Keywords: Learning Problem Based Learning Based on Pancasila Values and Industry Revolution 4.0

\section{PENDAHULUAN}

Pembelajaran adalah suatu proses, pembelajaran adalah ssuatu sistem dan pembelajaran adalah suatu perubahan.(Rusk, 2015) (Partnership for 21st Century Learning Skills, 2011) Pemaknaan pembelajaran yang demikian mengandung arti bahwa dalam pembelajaran ada prosesnya ada sistemnya dan pasti ada perubahannya. (D. Kolb, 1984) (Michaelsen \& Meidow, 2019) Pembelajaran sebagai suatu proses bermakna bahwa dalam pembelajaran terjadi proses interaksi yang komunikatif yang berjalan secara terarah, terencana, kontinu, dan terus menerus terhadap semua komponen pembelajaran dalam rangka tercapainya tujuan pembelajaran secara optimal. (A. Y. Kolb \& Kolb, 2005) (Ellström, 2010) Pembelajaran sebagai suatu sistem bermakna bahwa dalam pembelajaran terdapat sub sistem sub sistem yang saling berkaitan satu sama lain dalam rangka tercapai tujuan pembelajaran secara maksimal. (March, 1991) Pembelajaran suatu perubahan bermakna bahwa dalam pembelajaran sangat diharapkan terjadinya perubahan pada ranah afektif, psikomotorik dan kognitif yang permanen pada setiap diri siswa. (D. G. Learning, 2001) (Gibbs, 1988)

Pembelajaran di era revolusi indutri 4.0 dituntut adanya desaian pembelajaran yang lebih inovatif. Hal ini disebabkan 
tantangan yang dihadapi peserta didik semakin kompleks dan modern. Pembelajaran di era revolusi indutri 4.0 tidak hanya berorientasi siswa tahu akan tetapi yang terpenting siswa memiliki sikap mental untuk siap menghadapi berbagai tantanga di era revolusi industri 4.0. karena iti guru dituntut untuk dapat memberikan berbagai skill yang berbasis filter nilai pancasila. Artinya siswa ke depannya tidak menolak substansi revolusi indutri 4.0 akan tetapi juga tidak menerima secara mentahmentah. Dengan demikian siswa tetap menerima berbagai kemajuan yang ada di era revolusi industri akan tetapi tetap harus di filter dengan nilai-nilai pancasila.

Pembelajaran PPKn saat ini berkesan hanya sekedar penyampaian informasi pada siswa, sehingga siswa tidak mendapatkan keterampialan keterampilan yang diharapkan sebagai bekal dalam menghadapi berbagai tantangan yang kompleks di era revolusi industri.

Hasil pengamatan dilapangan terhadap siswa kelas VIII di SMP Negeri 1 Kartasura ditemukan hal-hal sebagai berikut: pembelajaran berpusat pada guru, pmblajaran tekstual, pembelajaran menekankan hafalan, pembelajaran kurang menggairahkan siswa, pembelajaran kurang mmotivasi siswa untuk bertanya, dan pembelajaran kurang menarik bagi siswa. Dampaknya adalah siswa kurang berani menyatakan pndapatnya, siswa mudah menyrah, siswa kurang kreatif dan inovatis, banyak sikap dan perilaku siswa yang kurang mencerminkan nilai-nilai pancasila.

Penelitian ini difokuskan pada pembelajaran inovatif problem based leaning yang berbasis nilai-nilai pancasila dalam menghadapi revolusi industri 4.0 saat ini. Pokok permasalahannya dirumuskan bagaimanakah implementasi pembelajaran inovatif problem based leaning yang berbasis nilai-nilai pancasila dalam menghadapi revolusi industri 4.0 bagi siswa kelas VIII SMP Negeri 1 Kartasura tahun Pelajaran 2018-2019

\section{METODE}

Penelitian ini adalah penelitian deskriptif kualitatif. Subjek penelitiannya adalah Guru PPKn dan siswa kelas VIII SMP Negeri 1 kartasura Tahun Pelajaran 2018-2019, Metode pengumpulan data menggunakan: observasi, wawancara dan dokumentasi. Validitas ata dilakukan dengan trianggulasi sumber dan metode. Teknik analisis data menggunakan teknik analisis kualitatif terdiri dari 4 tahap yaitu: pengumpulan data, reduksi data, display data dan verifikasi data.

\section{KAJIAN TEORI}

Pembelajaran Inovatif adalah pendidik profesional dengan tugas utama mendidik, mengajar, membimbing, mengarahkan, melatih, menilai dan mengevaluasi peserta didik pada pendidikan anak usia dini jalur pendidikan formal, pendidikan dasar, dan pendidikan menengah (Pasal 1, Ayat 1 UU RI No.14/2005). Problem-based learning adalah salah satu pendekatan pembelajaran dengan membuat konfrontasi kepada siswa dengan masalahmasalah praktis, berbentuk illstructured, atau open-ended melalui stimulus dalam belajar (Fogarty, 1997).

Pendapat lain Pembelajaran inovatif adalah pembelajaran yang lebih bersifat student centered. Artinya, pembelajaran yang lebih memberikan peluang kepada siswa untuk mengkonstruksi pengetahuan secara mandiri (self directed) dan dimediasi oleh teman sebaya (peer mediated instruction). Pembelajaran inovatif mendasarkan diri pada paradigma konstruktivistik. (Al-Tabany, 2014) (Made, 2009). Pembelajaran inovatif biasanya 
berlandaskan paradigma konstruktivistik membantu siswa untuk menginternalisasi, membentuk kembali, atau mentransformasi informasi baru.

Model-model pembelajaran inovatif sangat banyak, dalam penelitian ini difokuskan pada implementasi pembelajaran berbasis problem based learning be rlandaskan pada nilai-nilai pancasila.

Problem-based instruction adalah metode pembelajaran yang berlandaskan paham konstruktivistik yang mengakomodasi keterlibatan siswa dalam belajar dan pemecahan masalah yang otentik

Dalam pemerolehan informasi dan pengembangan pemahaman tentang topiktopik, siswa belajar bagaimana mengkonstruksi kerangka masalah, mengorganisasikan dan menginvestigasi masalah, mengunpulkan dan menganalisis data, menyusun fakta, mengkonstruksi argumentasi mengenai pemecahan masalah, bekerja secara individual atau kolaborasi dalam pemecahan masalah. Selengkapnya:

Model Pembelajaran Berbasis Masalah menurut Arends (2004) mengemukakan bahwa metode problembased learning memiliki lima langkah, yaitu: (1) guru mendefinisikan atau mempresentasikan masalah atau isu yang berkaitan (masalah bisa untuk satu unit pelajaran atau lebih, bisa untuk pertemuan satu, dua, atau tiga minggu, bisa berasal dari hasil seleksi guru atau dari eksplorasi siswa) (2) guru membantu siswa mengklarifikasi masalah dan menentukan bagaimana masalah itu diinvestigasi (investigasi melibatkan sumber-sumber belajar, informasi, dan data yang variatif, melakukan survei dan pengukuran), (3) guru membantu siswa menciptakan makna terkait dengan hasil pemecahan masalah yang akan dilaporkan (bagaimana mereka memecahkan masalah dan apa rasionalnya), (4) mengorganisasikan laporan (makalah, laporan lisan, model, program komputer, dan lain-lain), dan (5) presentasi (dalam kelas melibatkan semua siswa, guru, bila perlu melibatkan administrator dan anggota masyarakat).

Menurut Duch (1995) dalam Aris Shoimin (2014:130) mengemukakan bahwa pengertian dari model Problem Based Learning adalah: Problem Based Learning (PBL) atau pembelajaran berbasih masalah adalah model pengajaran yang bercirikan adanya permasalahan nyata sebagai konteks untuk para peserta didik belajar berfikir kritis dan keterampilan memecahkan masalah serta memperoleh pengetahuan. Finkle and Torp (1995) dalam Aris Shoimin (2014:130) menyatakan bahwa: PBM merupakan pengembangan kurikulum dan sistem pengajaran yang mengembangkan secara stimulan strategi pemecahan masalah dan dasardasar pengetahuan dan keterampilan dengan menempatkan para peserta didik dalam peran aktif sebagai pemecah permasalahan sehari-hari yang tidak terstruktur dengan baik. Sedangkan menurut (Sulaiman, 2010) berpendapat bahwa: Model Problem Based Learning diartikan sebagai sebuah model pembelajaran yang didalamnya melibatkan siswa untuk berusaha memecahkan masalah dengan melalui beberapa tahap metode ilmiah sehingga siswa diharapkan mampu mempelajari pengetahuan yang berkaitan dengan masalah tersebut dan sekaligus siswa diharapkan akan memilki keterampilan dalam memecahkan masalah.

Dalam penelitian ini pembelajaran problem based learning berlandaskan pancasila dimaknai sebagai model pembelajaran yang berusaha menerapkan masalah yang terjadi dalam dunia nyata sebagai sebuah konteks bagi para siswa dalam berlatih bagaimana cara berfikir kritis dan mendapatkan keterampilan dalam pemecahan masalah, serta tak terlupakan untuk mendapatkan pengetahuan sekaligus konsep yang penting dari materi ajar yang 
dibicarakan berlandaskan nilai-nilai pancasila. Hal ini berarati guru dalam proses pembelajaran menerapkan nilai-nilai pancasila yaitu: nilai religious yang diwujudkan dengan mngajak berdoa bersama sesuai agama dan kepercayaannya masing-masing, nilai kemanusiaan diwujudkan dalam selama proses pembelajaran guru tidak boleh pilih kasih terhadap para siswanya, nilai persatuan diwujudkan dalam guru menghargai dan menghormati perbedaan ras, suku, budaya, bahasa dan agama yang dimiliki oleh para siswa, nilai demokrasi guru menghargai dan meghgormati pendapat para siswa nya, guru tidak memaksakan kehendaknya, nilai keadilan guru dalam memberikan nilai maupun hukuman bersikap objektif.

Terwujudnya pembelajaran problem based learning berlandaskan nilai-nilai pancasila dapat mendorong siswa untuk berpartisipasi secara aktif dalam poses pembelajaran.

Pembelajaran problem based learing memiliki karakteristik tersendiri. Berdasarkan teori yang dikembangkan (Hasanah \& Utami, 2017) menjelaskan karakteristik dari PBM, (P. Learning, 2001) (Nakada, Okada, Yoshihara, Namiki, \& Hiroi, 2017) yaitu:

1. Learning is student-centered

Proses pembelajaran dalam PBL lebih menitikberatkan kepada siswa sebagai orang belajar. Oleh karena itu, PBL didukung juga oleh teori konstruktivisme dimana siswa didorong untuk dapat mengembangkan pengetahuannya sendiri.

2. Autenthic problems from the organizing focus for learning

Masalah yang disajikan kepada siswa adalah masalah yang autentik sehingga siswa mampu dengan mudah memahami masalah tersebut serta dapat menerapkannya dalam kehidupan profesionalnya nanti.

3. New information is acquired through self-directed learning
Dalam proses pemecahan masalah mungkin saja belum mengetahui dan memahami semua pengetahuan prasayaratnya sehingga siswa berusaha untuk mencari sendiri melalui sumbernya, baik dari buku atau informasi lainnya.

4. Learning occurs in small group Agar terjadi interaksi ilmiah dan tukar pemikiran dalam usaha mengembangkan pengetahuan secara kolaboratif, PBM dilaksanakan dalam kelompok kecil. Kelompok yang dibuat menuntut pembagian tugas yang jelas dan penerapan tujuan yang jelas.

5. Teachers act as facilitators

Pada pelaksanaan PBM, guru hanya berperan sebagai fasilitator. Meskipun begitu guru harus selalu memantau perkembangan aktivitas siswa dan mendorong mereke agar mencapai target yang hendak dicapai.

Menurut (Savery, 2012) (De Graff \& Kolmos, 2003) (BARROWS, 1986) karakteristik Problem Based Learning adalah sebagai berikut: Permasalahan menjadi starting point dalam belajar ,Permasalahan yang diangkat adalah permasalahan yang ada di dunia nyata yang tidak terstruktur ,Permasalahan memebutuhkan perspektif ganda ,Permasalahan menantang pengetahuan yang dimilki oleh Peserta didik, sikap dan kompentensi yang kemudian membutuhkan identifikasi kebutuhan belajar dan bidang baru dalam mengajar; ,Belajar pengarahan diri menjadi hal yang utama: ,Pemanfaatan sumber pengetahuan yang beragam, penggunaannya, dan evaluasi sumber informasi merupakan proses yang esensial dalam PBM; ,Belajar adalah kolaboratif, komunikasi, dan kooperatif; ,Pengembangan keterampilan inquiri dan pemecahan masalah sama pentingnya dengan penguasaan isi pengetahuan untuk mencari solusi dari sebuah permasalahan; ,Keterbukaan proses dalam PBM meliputi 
sintesis dan integrasi dari sebuah proses belajar; dan PBM melibatkan evaluasi dan review pengalaman Peserta didik dan proses belajar

Sedangkan ciri dari model Problem Based learning (Hmelo-Silver, 2004) (Tuma, J. M., \& Pratt, J. M. (1982). Clinical child psychology practice and training: A survey. Vlots of Clinical Child \& Adolescent Psychology, 137(August 2012) et al., 2004) (English \& Kitsantas, 2013) secara umum dapat dikenali dengan adanya enam ciri yang dimilikinya, adapun keenam ciri tersebut adalah: Kegiatan belajar mengajar dengan model Problem Based Learning dimulai dengan pemberian sebuah masalah. Masalah yang disajikan berkaitan dengan kehidupan nyata para siswa, Mengorganisasikan pembahasan seputar disiplin ilmu. Siswa diberikan tanggungjawab yang maksimal dalam membentuk maupun menjalankan proses belajar secara langsung. Siswa dibentuk menjadi beberapa kelompok kecil, dan Siswa dituntut untuk mendemonstrasikan produk atau kinerja yang telah mereka pelajari.

Proses PBL mereplikasi pendekatan sistematik yang sudah banyak digunakan dalam menyelesaikan masalah atau memenuhi tuntutan-tuntutan dalam dunia kehidupan dan karier. Sintak operasional PBL bisa rmencakup antara lain sebagai berikut: Pertama-tama Peserta didik disajikan suatu masalah. ,Peserta didik mendiskusikan masalah dalam tutorial PBL dalam sebuah kelompok kecil. Mereka mengklarifikasi fakta-fakta suatu kasus kemudian mendefinisikan sebuah masalah. Mereka membrainstorming gagasangagasannya dengan berpijak pada pengetahuan sebelumnya. Kemudian, mereka mengidentifikasi apa yang mereka butuhkan untuk menyelesaikan masalah serta apa yang mereka tidak ketahui. Mereka menelaah masalah tersebut. Mereka juga mendesain suatu rencana tindakan untuk menggarap masalah ,Peserta didik terlibat dalam studi independen untuk menyelesaikan masalah diluar bimbingan guru. Hal ini bisa mencakup: perpustakaan, database, website, masyarakat, dan observasi. Peserta didik kembali pada tutorial PBL, lalu saling sharing, informasi, melalui peer teaching atau cooperative learning atas masalah tertentu. e. Peserta didik menyajikan solusi atas masalah. Peserta didik mereview apa yang mereka pelajari proses pengerjaan selama ini. Semua yang berpartisipasi dalam proses tersebut terlibat dalam review berpasangan, dan review berdasarkan bimbingan guru, sekaligus melakukan refleksi atas kontribusinya tehadap proses tersebut.

(Choridah, 2016) mengemukakan bahwa langkah-langkah dalam model pembelajaran Problem Based Learning adalah sebagai berikut: Guru menjelaskan tujuan pembelajaran. Menjelaskan logistik yang dibutuhkan. Memotivasi siswa terlibat dalam aktivitas pemecahan masalah yang dipilih. Guru membantu siswa mendefinisikan dan mengorganisasikan tugas belajar yang berhubungan dengan masalah tersebut (menetapkan topik, tugas, jadwal, dll). Guru mendorong siswa untuk mengumpulkan informasi yang sesuai, eksperimen untuk mendapatkan penjelasan dan pemecahan masalah, pengumpulan data, hipotesis, dan pemecahan masalah. Guru membantu siswa dalam merencanakan serta menyiapkan karya yang sesuai seperti laporan dan membantu mereka berbagai tugas dengan temannya. Guru membantu siswa untuk melakukan refleksi atau evaluasi terhadap penyelidikan mereka dan proses-proses yang mereka gunakan.

Langkah-langkah operasional dalam proses pembelajaran yang dikonsepkan oleh Kementrian Pendidikan dan Kebudayaan adalah sebagai berikut:

\section{a. Konsep Dasar (Basic Concept).}


Fasilitator memberikan konsep dasar, petunjuk, referensi, atau link dan skill yang diperlukan dalam pembelajaran tersebut. Hal ini dimaksudkan agar peserta didik lebih cepat masuk dalam atmosfer pembelajaran dan mendapatkan peta yang akurat tentang arah dan tujuan pembelajaran.

\section{b. Pendefinisian Masalah (Defining The Problem).}

Dalam langkah ini fasilitator menyampaikan Skenario atau permasalahan dan peserta didik melakukan berbagai kegiatan brainstorming dan semua anggota kelompok mengungkapkan pendapat, ide, dan tanggapan terhadap Skenario secara bebas, sehingga dimungkinkan muncul berbagai macam alternative pendapat.

\section{c. Pembelajaran Mandiri (Self} Learning). Peserta didik mencari berbagai

sumber yang dapat memperjelas isu yang sedang dinvestigasi. Sumber yang dimaksud dapat dalam bentuk artikel tetulis yang tersimpan dipepustakaan, halaman web, atau bahkan pakar dalam bidang yang relevan. Tahap investigasi memiliki dua tujuan utama,yaitu: (1) agar peserta didik mencari informasi dan mengembangkan pemahaman yang relevan dengan permasalahan yang telah didiskusikan dikelas, dan (2) informasi dikumpulkan dengan satu tujuan yaitu dipresentasikan di kelas dan informasi tersebut haruslah relevan dan dapat dipahami.

\section{d. Pertukaran Pengetahuan (Exchange Knowledge).}

Setelah mendapatkan sumber untuk keperluan pendalaman materi dalam langkah pembelajaran mandiri, selanjutnya pada pertemuan berikutnya peserta didik berdiskusi dalam kelompoknya untuk mengklarifikasi capaiannya dan merumuskan solusi dari permasalahan kelompok. Pertukaran pengetahuan ini dapat dilakukan dengan cara peserta didik berkumpul sesuai kelompok dan fasilitatornya.

e. Penilaian (Assessment).

Penilaian dilakukan dengan memadukan tiga aspek pengetahuan (knowledge), kecakapan (skill), dan sikap (attitude). Penilaian terhadap penguasaan pengetahuan yang mencakup seluruh kegiatan pembelajaran yang dilakukan dengan ujian akhir semester (UAS), ujian tengah semester (UTS), kuis, PR, dokumen, dan laporan.

Berdasarkan uraian tersebut di atas langkah-langkah pembelajaran (sintaks pembelajaran) yang dilakukan dalam penelitian ini adalah sebagai berikut:

\section{Penyajian Masalah.}

Pertama-tama Peserta didik disajikan suatu masalah. Selain itu dalam kegiatan ini guru menjelaskan tujuan pembelajaran, menjelaskan logistik yang diperlukan, dan memotivasi Peserta didik terlibat pada aktivitas pemecahan masalah. Hal ini dimaksudkan agar peserta didik lebih cepat masuk dalam atmosfer pembelajaran dan mendapatkan peta yang akurat tentang arah dan tujuan pembelajaran.

\section{Diskusi Masalah.}

Peserta didik mendiskusikan masalah dalam tutorial PBL dalam sebuah kelompok kecil. Mereka mengklarifikasi fakta-fakta suatu kasus kemudian mendefinisikan sebuah masalah. Mereka membrainstorming gagasan-gagasannya dengan berpijak pada pengetahuan sebelumnya. Kemudian, mereka mengidentifikasi apa yang mereka butuhkan untuk menyelesaikan masalah serta apa yang mereka tidak ketahui. Mereka menelaah masalah tersebut. Mereka juga mendesain suatu rencana tindakan untuk menggarap masalah. Guru dalam hal ini hanya memfasilitasi kegiatan tersebut, sehingga berjalan dengan lancar.

3. Penyajian Solusi dari Masalah.

Membantu peserta didik dalam merencanakan dan menyiapkan penyajian 
solusi dari masalah, dan membantu mereka untuk berbagi tugas dengan temannya.

\section{Mereview.}

Peserta didik bersama-sama dengan guru melakukan mereview terhadap penyelidikan mereka dan proses yang mereka gunakan.

Pembelajaran problem based learning sesuai dengan tuntutan revolusi industri 4.0.(Sunarno, 2018) (Huseno, 2018) (Suwardana, 2017). Secara singkat, pengertian industri 4.0 adalah tren di dunia industri yang menggabungkan teknologi otomatisasi dengan teknologi cyber.

Pada industri 4.0, teknologi manufaktur sudah masuk pada tren otomatisasi dan pertukaran data. Hal tersebut mencakup sistem cyber-fisik, internet of things (IoT), komputasi awan, dan komputasi kognitif. (Forkomsi FEB UGM, 2019) (Prasetyo \& Trisyanti, 2018)

Tren ini telah mengubah banyak bidang kehidupan manusia, termasuk ekonomi, dunia kerja, bahkan gaya hidup manusia itu sendiri. Singkatnya, revolusi 4.0 menanamkan teknologi cerdas yang dapat terhubung dengan berbagai bidang kehidupan manusia.

Revolusi industri keempat atau industri 4.0 terjadi pada tahun 2012, industri 4.0 memperkenalkan proses produksi Cyber-Physical. Industri 4.0 ini mengarah kepada proses manufaktur yang berbasis internet atau jaringan wireless. Penggunaan teknologi ini tidak hanya sebatas pada komunikasi, akan tetapi juga mencakup kontrol dan kendali jarak jauh (Suwardana, 2017)

Perkembangan industri dan teknologi telah berkembang dengan sangat cepat terutama di bidang otomasi. Berdasarkan survey yang dilakukan oleh Credit Suisse total biaya yang dikeluarkan untuk otomasi secara global pada tahun 2012 adalah 152 milyar dollar. Sedangkan biaya yang dikeluarkan untuk otomasi dalam bidang proses makanan dan minuman adalah $5.8 \%$ dari total otomasi secara global.

Dikutip dari Wikipedia, revolusi industri 4.0 memiliki empat prinsip yang memungkinkan setiap perusahaan untuk mengidentifikasi

dan mengimplementasikan berbagai skenario industri 4.0, diantaranya adalah: Interoperabilitas (kesesuaian); kemampuan mesin, perangkat, sensor, dan manusia untuk terhubung dan saling berkomunikasi satu sama lain melalui media internet untuk segalanya (IoT) atau internet untuk khalayak (IoT). Transparansi Informasi; kemampuan sistem informasi untuk menciptakan salinan dunia fisik secara virtual dengan memperkaya model pabrik digital dengan data sensor. Bantuan Teknis; pertama kemampuan sistem bantuan untuk membantu manusia mengumpulkan data dan membuat visualisasi agar dapat membuat keputusan yang bijak. Kedua, kemampuan sistem siber-fisik untuk membantu manusia melakukan berbagai tugas yang berat, tidak menyenangkan, atau tidak aman bagi manusia, dan Keputusan Mandiri; kemampuan sistem siber-fisik untuk membuat keputusan dan melakukan tugas semandiri mungkin.

Revolusi industri 4.0 akan membawa banyak perubahan dengan segala konsekuensinya, industri akan semakin kompak dan efisien. Namun ada pula risiko yang mungkin muncul, misalnya berkurangnya Sumber Daya Manusia karena digantikan oleh mesin atau robot. Dunia saat ini memang tengah mencermati revolusi industri 4.0 ini secara saksama. Berjuta peluang ada di situ, tapi di sisi lain terdapat berjuta tantangan yang harus dihadapi.

Prof. Klaus Martin Schwab, teknisi dan ekonom Jerman, yang juga pendiri dan Executive Chairman World Economic Forum, yang pertama kali memperkenalkannya. Dalam bukunya The 
Fourth Industrial Revolution (2017), ia menyebutkan bahwa saat ini kita berada pada awal sebuah revolusi yang secara fundamental mengubah cara hidup, bekerja dan berhubungan satu sama lain.

Perubahan itu sangat dramatis dan terjadi pada kecepatan eksponensial. Perubahan yang sangat berpengaruh dalam kehidupan di banding era revolusi industri sebelumnya. Pada revolusi Industri 1.0, tumbuhnya mekanisasi dan energi berbasis uap dan air menjadi penanda.

Tenaga manusia dan hewan digantikan oleh kemunculan mesin. Mesin uap pada abad ke-18 adalah salah satu pencapaian tertinggi. Revolusi 1.0 ini bisa meningkatkan perekonomian yang luar biasa. Sepanjang dua abad setelah revolusi industri pendapatan perkapita negara-negara di dunia meningkat enam kali lipat.

Revolusi Industri 2.0 perubahannya ditandai dengan berkembangnya energi listrik dan motor penggerak. Manufaktur dan produksi massal terjadi. Pesawat telepon, mobil, dan pesawat terbang menjadi contoh pencapaian tertinggi.

Perubahan cukup cepat terjadi pada revolusi Industri 3.0. Ditandai dengan tumbuhnya industri berbasis elektronika, teknologi informasi, serta otomatisasi. Teknologi digital dan internet mulai dikenal pada akhir era ini. Revolusi Industri 4.0 ditandai dengan berkembangnya Internet offfor Things, kehadirannya begitu cepat.

Banyak hal yang tak terpikirkan sebelumnya, tiba-tiba muncul dan menjadi inovasi baru, serta membuka lahan bisnis yang sangat besar. Munculnya transportasi dengan sistem ride-sharing seperti Go-jek, Uber, dan Grab. Kehadiran revolusi industri 4.0 memang menghadirkan usaha baru, lapangan kerja baru, profesi baru yang tak terpikirkan sebelumnya.

Lalu

mngimplementasikan esensi revolusi industri 4.0 dalam pemeblajaran problem based learning berbasis nilai-nilai pancasila. Pertama: Guru harus memanfaatkan IT dalam proses pembelajaran secara maksimal, kedua: Guru dalam proses pembelajaran harus mengedepankan pemberian bekal keterampilan pada siswa, ketiga: dalam poses pembelajaran guru harus mengutamakan pembangunan mental pada peserta didi, keempat: dalam pembelajaran guru harus menggunakan peluang revolusi indutri 4.0 serta mengeliminir ancaman yang ada, kelima: dalam pemblajaran guru harus mengedepankan aspek keterampilan dengan tidak mengabaikan dua aspek yang lainnya, kenam: dalam pembelajaran guru harus mengangkat masalah yang actual yang dalam penyelesaiannya berlandaskan pada nilai-nilai pancasila, dan ketujuh guru dalam proses pemeblajaran sikap, perilaku dan perbuatannya harus mencerminkan nilainilai Pancasila

\section{HASIL PENELITIAN}

Dari hasil pengamatan yang dilakukan mulai tanggal 23-30 Mei 2019 trhadap sikap, perilaku dan perbuatan guru dan siswa dalam proses pemeblajaran PPKn ditemukan hal-hal sebagai berikut: Siswa kurang aktif dalam merespon materi yang disampaikan oleh guru; Siswa masih kurang dalam memahami materi-materi pelajaran akuntansi perusahaan dagang yang disampaikan; Siswa kurang termotivasi dan menjadi kurang berminat untuk mengikuti pembelajaran akuntansi; Kurangnya guru dalam melibatkan siswa untuk aktif dalam kegiatan pembelajaran; Kurangnya guru dalam melakukan variasi strategi pembelajaran menggunakan model pembelajaran; Guru belum mampu menciptakan kelas dengan suasana belajar yang menyenangkan dan menarik minat belajar 
siswa; guru belum optimal dalam memanfaatkan teknologi informasi dan komunikasi dalam kegiatan belajar mengajar, pembelajaran belum berbasis IT, guru masih menggunakan media yang konvensional, guru belum menerapkan pemeblajaran berbasis dig ital, guru belum menerapkan E-learning, sikap dan perilaku guru masih kurang mencerminkan nilainilai pancasila.

Hasil wawancara dengan 10 guru PPKn yang dilakukan pada tanggal $31 \mathrm{Mei}$ 2019 dipeoleh informasi: guru kurang paham esensi dan subtsansi revolusi industri 4.0, guru merasa kesulitan mendesain pembelajaran berorientasi pada revolusi industri 4.0, sarana dan prasarana sekolah belum memiliki internet, computer jumlahnya sangat terbatas, guru kurang paham IT, guru kurang paham E-learning, pembelajaran PPKn dengan E-learning kurang cocok.

Hasil wawancara dengan siswa yang dilakukan pada tanggal 1 Juni 2019 diperoleh informasi: dalam mengajar guru teks book, guru kurang menguasai materi, guru kurang demokratis, sikap dan perilaku guru kurang mencerminkan nilai-nilai pancsila, guru lebih menekankan aspek pengetahuan, guru kurang memberikan keterampilan pada siswa, guru kurang mampu memotivasi siswa, guru kurang memberikan pembekalan mental ideology pada siswa dalam menghadapi revolusi industri 4.0, guru kurang mampu menjelaskan tantangan dan peluang revolusi industri 4.0, guru dalam pemeblajaran PPKn tidak mengkaitkan esensi dan substansi revolusi industri 4.0, gaya mengajar guru monoton, bahasa guru sulit dipahami.

Berdasarkan temuan pengamatan di lapangan dan informasi hasil wawancara dengan guru maupun siswa berdampak bahwa siswa kurang merespon pembelajaran yang diberikan gurum daya serap siswa terhadap materi yang diajarkan rendah terbukti hasil pre tes dari 80 siswa yang memenuhi KKM hanya 35 siswa dengan KKM 80, siswa tidak memiliki bekal dalam menghadapi revolusi industri 4.0, siswa tidak memiliki keterampilan dalam menghadapi revolusi industri 4.0, banyak sikap, perilaku dan perbuatan siswa yang kurang mencerminkan nilai-nilai pancasila.

$$
\text { Istilah "Revolusi Industri" }
$$
diperkenalkan oleh Friedrich Engels dan Louis-Auguste Blanqui di pertengahan abad ke-19. Revolusi industri ini pun sedang berjalan dari masa ke masa.

Dekade terakhir ini sudah dapat disebut memasuki fase keempat 4.0. Perubahan fase ke fase memberi perbedaan artikulatif pada sisi kegunaaannya. Fase pertama (1.0) bertempuh pada penemuan mesin yang menitikberatkan (stressing) pada mekanisasi produksi.

Fase kedua (2.0) sudah beranjak pada etape produksi massal yang terintegrasi dengan quality control dan standarisasi. Fase ketiga (3.0) memasuki tahapan keseragaman secara massal yang bertumpu pada integrasi komputerisasi. Fase keempat (4.0) telah menghadirkan digitalisasi dan otomatisasi perpaduan internet dengan manufaktur (Suwardana, 2017)

Era pendidikan 4.0 merupakan tantangan yang sangat berat dihadapi guru. Jack Ma (CEO Alibaba Group) dalam pertemuan tahunan World Economic Forum 2018 menyatakan bahwa pendidikan adalah tantangan besar abad ini.

Jika mengubah cara mendidik dan belajar-mengajar, maka 30 tahun mendatang kita akan mengalami kesulitan besar. Era Revolusi Industri 4.0 membawa dampak yang tidak sederhana. Ia berdampak pada seluruh aspek kehidupan manusia. Termasuk dalam hal ini adalah pendidikan. Era ini ditandai dengan semakin sentralnya 
peran teknologi cyber dalam kehidupan manusia. Maka tak heran jika dalam dunia pendidikan muncul istilah "Pendidikan 4.0".

Pendidikan $4.0 \quad$ (Education 4.0) adalah istilah umum digunakan oleh para ahli pendidikan untuk menggambarkan berbagai cara untuk mngintegrasikan teknologi cyber baik secara fisik maupun tidak ke dalam pembelajaran. Ini adalah lompatan dari pendidikan 3.0 yang menurut Jeff Borden mencakup pertemuan ilmu saraf, psikologi kognitif, dan teknologi pendidikan. Pendidikan 4.0 adalah fenomena yang merespons kebutuhan munculnya revolusi industri keempat dimana manusia dan mesin diselaraskan untuk mendapatkan solusi, memecahkan masalah dan tentu saja menemukan kemungkinan inovasi baru.

Buah dari revolusi industri 4.0 adalah munculnya fenomena disruptive innovation. Dampak dari fenomena ini telah menjalar di segala bidang kehidupan. Mulai industri, ekonomi, pendidikan, politik, dan sebagainya. Fenomena ini juga telah berhasil menggeser gaya hidup (life style) dan pola pikir (mindset) masyarakat dunia. Disruptive innovation secara sederhana dapat dimaknai sebagai fenomena terganggunya para pelaku industri lama (incumbent) oleh para pelaku industri baru akibat kemudahan teknologi informasi.

Lee et al (2013) menjelaskan, industri 4.0 ditandai dengan peningkatan digitalisasi manufaktur yang didorong oleh empat faktor: 1) peningkatan volume data, kekuatan komputasi, dan konektivitas; 2) munculnya analisis, kemampuan, dan kecerdasan bisnis; 3) terjadinya bentuk interaksi baru antara manusia dengan mesin; dan 4) perbaikan. instruksi transfer digital ke dunia fisik, seperti robotika dan 3D printing. Lifter dan Tschiener (2013) menambahkan, prinsip dasar industri 4.0 adalah penggabungan mesin, alur kerja, dan sistem, dengan menerapkan jaringan cerdas di sepanjang rantai dan proses produksi untuk mengendalikan satu sama lain secara mandiri.

Kuantitas bukan lagi menjadi indikator utama bagi suatu instansi pendidikan dalam mencapai kesuksesan, melainkan kualitas lulusannya. Kesuksesan dalam menghadapi revolusi industri 4.0 erat kaitannya dengan inovasi yang diciptakan oleh sumberdaya yang berkualitas, sehingga perguruan tinggi wajib dapat menjawab tantangan dalam mengahadapi kemajuan teknologi dan persaingan dunia keraj di era globalisasi.

Menurut (Prasetyo \& Trisyanti, 2018), bidang pendidikan perlu merevisi kurikulum dengan menambahkan lima kompetensi peserta didik dalam memasuki era Revolusi 4.0 ini yaitu memiliki kemampuan berfikir kritis, memiliki kreatifitas dan kemampuan yang inovatif, memiliki kemampuan dan keterampilan berkomunikasi, dapat bekerjasama dan berkolaborasi serta memiliki kepercayaan diri.

Selain itu agar lulusan pendidikan nantinya dapat berkompetitif maka kurikulum memerlukan orientasi baru tidak hanya cukup memahami orientasi lama (membaca, menulis, dan matematika) tetapi perlu mehami literasi indutri 4.0 yaitu literasi data dengan kemampuan untuk membaca, menganalisis dan menggunakan informasi dunia digital dengan cara memahami cara kerja mesin aplikasi teknologi.

Pendidikan yang sarat dengan muatan pengetahuan mengesampingkan muatan sikap dan keterampilan sebagaimana saat ini implementasi akan menghasilkan peserta didik yang tidak mempu berkompetensi dengan mesin oleh karena itu guru harus mengurangi dominasi pengetahuan pendidikan dan pembelajaran dengan harapan peserta didik mampu mengungguli kecerdasan mesin. Pendidikan 
yang diimbangi dengan karakter dan literasi menjadikan peserta didik sangat bijaksana dalam menggunakan mesin untuk kemaslahatan masyarakat.

Revolusi Industri Jilid Empat memiliki potensi untuk meningkatkan tingkat pendapatan global dan meningkatkan kualitas hidup bagi masyarakat dunia, akan menghasilkan harga murah dan kompetitif, meningkatkan efisiensi dan produktivitas, menurunkan biaya transportasi dan komunikasi, meningkatkan efektivitas logistik dan rantai pasokan global, biaya perdagangan akan berkurang, akan membuka pasar baru dan mendorong pertumbuhan ekonomi. Era Digital merupakan terminologi bagi masa yang segala sesuatunya dihidupkan dengan teknologi. Mulai dari televisi, pendingin ruangan, lemari pendingin, komputer, telepon pintar, hingga pada penggunaan internet yang masif, internet menjadi energi terbesar dari kehidupan di era ini. Internet membuat semua informasi yang ada di dunia ini menjadi sangat mudah didapatkan, bahkan dalam hitungan detik.

Bila ingin bersaing di era digital ini Indonesia perlu segera meningkatkan kemampuan dan keterampilan sumberdaya manusia melalu pendidikan, menjadi operator dan analis handal sebagai pendorong Industri mencapai daya saing dan produktivitas tinggi. Dengan melakukan hal ini tidak mustahil Indonesia akan melompat menjadi negara maju dalam Revolusi Industri Jilid Empat ini, melalui pemanfaatan implementasi teknologi digital dan komputasi kedalam Industri.

Yang mendasari revolusi digital adalah perkembangan komputer elektronik digital, yaitu komputer pribadi, dan khususnya mikroprosesor dengan kinerjanya yang terus meningkat, yang memungkinkan teknologi komputer untuk tertanam ke berbagai objek besar dari kamera ke pemutar musik pribadi. Sama pentingnya adalah pengembangan teknologi transmisi termasuk jaringan komputering, Internet dan penyiaran digital. Ponsel 3G dan 4G, yang tumbuh pesat penetrasi sosial pada tahun 2000, juga memainkan peran yang sangat besar dalam revolusi digital karena mereka secara bersamaan memberikan hiburan di mana-mana, komunikasi, dan konektivitas online.

(Haryanto, 2007) (Wahyudin D, 2011) menyatakan inovasi pembelajaran yang dilakukan di berkembangnya teknologi informatsi digital adalah memanfaatkan sarana teknologi informasi yang berkembang pesat di era revolusi industri 4.0 ini untuk meningkatkan mutu pembelajaran.

Selanjutnya (Bardi \& Jailani, 2015) mengartikan bahwa inovasi pendidikan dalam metode pembelajaran mencakup rumusan tentang pengorganisasian bahan ajar, strategi penyampaian dan pengelolaan kegiatan dengan memperhatikan tujuan, hambatan, dan karakteristik peserta didik sehingga diperoleh hasil yang efektif, efisien, dan menimbulkan daya tarik pembelajaran. Pendapat (Noh et al., 2013) tersebut didukung oleh (Nurdiansyah \& Fariyatul Fahyuni, 2016) dengan menyebut metode pembelajaran induktif atau berpikir induktif Kemudian Mauch J.E. (2014) menggunakannya untuk mengelompokan pola mengajar dan belajar yaitu klasikal, mandiri, dan interaksi guru-peserta didik atau pengajaran kelompok.

Berbagai pendapat di atas, menunjukkan bahwa inovasi pembelajaran berhubungan memungkinkan peserta didik memperoleh kemudahan dalam rangka mempelajari bahan ajar yang disampaikan oleh guru, tentunya 
dengan memanfaatkan media teknologi informasi

Ketepatgunaan dalam melakukan inovasi pendidikan sangatlah berpeluang bagi terciptanya banyak kondisi pembelajaran yang kondusif, menyenangkan sehingga kegiatan pembelajaran (instructional activities) dapat berlangsung secara efektif dan efisien dalam memfasilitasi peserta didik untuk dapat meraih suatu komponen yang sangat menentukan terciptanya kondisi selama berlangsungnya pembelajaran.

Dalam konteks kondisi

pembelajaran yang menyenangkan

(Universitas Negeri Malang, 2016)

menegaskan bahwa suatu kegiatan pembelajaran tidak selalu menjamin peserta didik akan dapat belajar. Hal ini menunjukkkan bahwa sebaik apapun seorang guru dalam merancang dan mendesain suatu program pembelajaran, kiranya tidak akan dapat secara optimal mewujudkan ketercapaian kompetensi yang diharapkan apabila tidak didukung oleh pemilihan sekaligus penggunaan metode secara tepat. Untuk itu peranan masyarakat digital di era revolusi industri 4.0 ini menjadi tantangan bagi membangun pendidikan berbasis teknologi informasi yang mampu menjawab tantangan kebutuhan masyarakat era revolusi industri 4.0 ini.

Dalam konteks pemeblajaran PPKn dengan menggunakan pendekatan problem based learning berbasis nilai-nilai pancasila yang harus dilakukan adalah guru harus merubah mindset pembelajaran dari tekstual menjadi kontekstual, dari guru sentries menjadi student sentries, dari knowlagde oriented menjadi psikomotoric oriented, pembelajaran harus berbasis IT, pembelajaran harus dapat menumbuhkan sikap mental peserta didik, pembelajaran PPKn tidak hanya teoritis akan tetapi harus praktis pragmatis, pembelajaran
PPKn harus menumbuhkan budaya kompetitif peserta didik, pemeblajaran PPKn harus menumbuhkan karakter peserta didik yang tangguh, ulet, dan pantang menyerah, pembelajaran PPKn harus membudayakan peserta didik untuk melek perkembangan IPTEK dan seni yang cangguh dan modern, pembelajaran PPKn harus mampu menumbuhkan budaya filterisasi terhadap berbagai Operkembangan IPTEK yang ada.

Guna mewujudkan pembelajaran PPKn di atas maka yang harus dilakukan oleh guru adalah : meningkatkan kwalitas diri melalui keikutsertaannya dalam pendidikan dan latihan IT, pemahaman yang benar tentang makna Revolusi industri 4.0 serta selalu mengadakan koordinasi guru-guru PPKn melalui wadah MGMP.

\section{KESIMPULAN}

Berdasarkn hasil pengamatan dilapangan, wawancara dengan guru dan siswa maka dapat ditarik kesimpulan bahwa pemeblajaran PPKn dengan menggunakan pendekatan pembelajaran Problem based learning berbasis nilai-nilai pancasila dapat dogunakan untuk membekali sikap mental dan keterampilkan peserta didik dalam menghadapi revolusi industri 4.0.

\section{DAFTAR PUSTAKA}

Al-Tabany, T. ibnu badar. (2014). Mendesain Model Pembelajaran Inovatif, Progresif, dan Kontekstual. In PRENADAMEDIA GROUP.

Bardi, B., \& Jailani, J. (2015). Jurnal inovasi teknologi pendidikan. In Jurnal Inovasi Teknologi Pendidikan.

BARROWS, H. S. (1986). A taxonomy of problem- based learning methods. Medical Education. https://doi.org/10.1111/j.13652923.1986.tb01386.x 
Choridah, D. T. (2016). PERAN

PEMBELAJARAN BERBASIS

MASALAH UNTUK

MENINGKATKAN KEMAMPUAN

KOMUNIKASI DAN BERPIKIR

KREATIF SERTA DISPOSISI

MATEMATIS SISWA SMA. Infinity

Journal.

https://doi.org/10.22460/infinity.v2i2.3 5

De Graff, E., \& Kolmos, A. (2003).

Characteristics of Problem-Based

Learning. International Journal of

Engineering Education.

https://doi.org/10.3102/0002831211419 491

Ellström, P. E. (2010). Organizational learning. In International Encyclopedia of Education. https://doi.org/10.1016/B978-0-08044894-7.00006-3

English, M. C., \& Kitsantas, A. (2013). Supporting Student Self-Regulated Learning in Problem- and ProjectBased Learning. Interdisciplinary Journal of Problem-Based Learning. https://doi.org/10.7771/15415015.1339

Forkomsi FEB UGM. (2019). Revolusi Industri 4.0. In Revolusi Industri 4.0.

Gibbs, G. (1988). Learning by Doing: A guide to teaching and learning methods. In Oxford Brookes University. https://doi.org/978-1-873576-86-1

Haryanto, D. P. (2007). INOVASI PEMBELAJARAN. Perspektif Ilmu Pendidikan. https://doi.org/10.21009/pip.162.11 Hasanah, A., \& Utami, L. (2017). Pengaruh Penerapan Model Problem Based Learning Terhadap Keterampilan Proses Sains Siswa. Jurnal Pendidikan Sains (JPS).

Hmelo-Silver, C. E. (2004). Problem-based learning: What and how do students learn? Educational Psychology Review.
https://doi.org/10.1023/B:EDPR.00000 34022.16470.f3

Huseno, T. (2018). Strategi Perguruan

Tinggi dalam Upaya Meningkatkan

Kualitas Sumberdaya Manusia Menghadapi Era Revolusi Industri 4.0. REKAMAN.

Kolb, A. Y., \& Kolb, D. A. (2005). Learning styles and learning spaces: Enhancing experiential learning in higher education. Academy of Management Learning and Education. https://doi.org/10.5465/AMLE.2005.17 268566

Kolb, D. (1984). Experiential learning: experience as the source of learning and development. Prentice Hall. https://doi.org/10.1016/B978-0-75067223-8.50017-4

Learning, D. G. (2001). The Digital GameBased Learning Revolution. Learning. https://doi.org/10.1016/j.iheduc.2004.1 2.001

Learning, P. (2001). Features of ProblemBased Learning. Winter.

Made, W. (2009). Strategi Pembelajaran Inovatif Kontemporer: Suatu Tinjauan Konseptual Operasional. Jakarta: PT. Bumi Aksara.

March, J. G. (1991). Exploration and Exploitation in Organizational Learning. Organization Science. https://doi.org/10.1287/orsc.2.1.71

Michaelsen, E., \& Meidow, J. (2019). Learning. In Advances in Computer Vision and Pattern Recognition. https://doi.org/10.1007/978-3-03004040-6_13

Nakada, A., Okada, Y., Yoshihara, A., Namiki, A., \& Hiroi, N. (2017).

Problem-based learning. Journal of the Medical Society of Toho University. https://doi.org/10.14994/tohoigaku:201 7-005

Noh, N. M., Merylina, H., Mustafa, A., Hamzah, M., Ismail, A., \& Abdullah, 
N. (2013). PENGGUNAAN INOVASI

TEKNOLOGI DALAM

PENGAJARAN : CABARAN GURU

DALAM E- PEMBELAJARAN.

PROCEEDINGS OF THE 7 TH

INTERNATIONAL MALAYSIAN

EDUCATIONAL TECHNOLOGY

CONVENTION (IMETC 2013 ).

Nurdiansyah, \& Fariyatul Fahyuni, E.

(2016). Inovasi Model Pembelajaran. In

Nizamial Learning Center.

Partnership for 21st Century Learning Skills. (2011). Framework for 21st Century Learning. P21 Framework Definitions.

Prasetyo, B., \& Trisyanti, U. (2018).

Revolusi industri 4.0 dan tantangan perubahan sosial. "Strategi

Pembangunan Nasional Menghadapi

Revolusi Industri 4.0."

Rusk, N. (2015). Deep learning. Nature

Methods.

https://doi.org/10.1038/nmeth.3707

Savery, J. R. (2012). Overview of Problembased Learning: Definitions and Distinctions. Interdisciplinary Journal of Problem-Based Learning. https://doi.org/10.7771/15415015.1002

Sulaiman, F. (2010). Students' perceptions of implementing problem-based learning in a physics course. Procedia Social and Behavioral Sciences. https://doi.org/10.1016/j.sbspro.2010.1 0.048

Sunarno, W. (2018). Makalah Utama Peran Pendidik dan Ilmuwan Sains dalam Menyongsong Revolusi ISSN : 2527 6670 Pembelajaran IPA di Era Revolusi Industri 4 . 0. Prosiding Seminar Nasional Pendidikan Fisika IV.

Suwardana, H. (2017). Revolusi Industri 4.0 Berbasis Revolusi Mental. ATI UNIK 2017, Vol . 1 No. 2 Hal 102-110. https://doi.org/http://ojs.unik- kediri.ac.id/index.php/jatiunik/article/vi ew/117/0

Tuma, J. M., \& Pratt, J. M. (1982). Clinical child psychology practice and training: A survey. Udots of Clinical Child \& Adolescent Psychology, 137(August 2012), 37-41. http://doi.org/10.1037/a0022390, Gobry, F. (1999). \{T\}his is a title. $\{$ M \}y Journal, 1, 120-130., Osment, S. E. (1980). T. A. of R. 1250-1550. ... and R. H. of L. M. and R. .... R. from http://scholar. google. $\mathrm{com} / \mathrm{scholar}$ ?hl=en\&btnG=Search\&q=i ntitle:THE+AGE+OF+REFORM+125. -1550\#2\%5Cnhttp://scholar. google. com/scholar?hl=en\&btnG=S., Caprara, G., \& Fida, R. (2008). Longitudinal analysis of the role of perceived selfefficacy for self-regulated learning in academic continuance and achievement. ... of Educational ..., 100(3), 525-534.

http://doi.org/10.1037/0022-

0663.100.3.525, Shanker, S. (2003).

Philosophy of science, logic and mathematics in the twentieth century. ... P. L. and N. Y. R. http://doi. org/10. 4324/978020302947., Marenbon, J. (1998). R. H. of P. I. ... P. L. and N. Y. R. http://doi. org/10. 4324/978020306227., ... Keshav, S. (2007). How to Read a Paper. Work, 37(3), 83-84.

http://doi.org/10.1145/1273445.127345

8. (2004). Foundations of problembased learning. SRHE and Open University Press Imprint.

Universitas Negeri Malang. (2016). Inovasi

Pendidikan di Era Big Data dan Aspek Psikologinya. Inovasi Pendidikan Di

Era Big Data Dan Aspek Psikologinya. Wahyudin D, S. R. (2011). Inovasi

Pendidikan Dan Pembelajaran. Kurikulum Pembelajaran. 
Al-Tabany, T. ibnu badar. (2014). Mendesain Model Pembelajaran Inovatif, Progresif, dan Kontekstual. In PRENADAMEDIA GROUP.

Bardi, B., \& Jailani, J. (2015). Jurnal inovasi teknologi pendidikan. In Jurnal Inovasi Teknologi Pendidikan.

BARROWS, H. S. (1986). A taxonomy of problem- based learning methods. Medical Education. https://doi.org/10.1111/j.13652923.1986.tb01386.x

Choridah, D. T. (2016). PERAN PEMBELAJARAN BERBASIS MASALAH UNTUK MENINGKATKAN KEMAMPUAN KOMUNIKASI DAN BERPIKIR KREATIF SERTA DISPOSISI MATEMATIS SISWA SMA. Infinity Journal. https://doi.org/10.22460/infinity.v2i2.3 5

De Graff, E., \& Kolmos, A. (2003). Characteristics of Problem-Based Learning. International Journal of Engineering Education. https://doi.org/10.3102/0002831211419 491

Ellström, P. E. (2010). Organizational learning. In International Encyclopedia of Education. https://doi.org/10.1016/B978-0-08044894-7.00006-3

English, M. C., \& Kitsantas, A. (2013). Supporting Student Self-Regulated Learning in Problem- and ProjectBased Learning. Interdisciplinary Journal of Problem-Based Learning. https://doi.org/10.7771/15415015.1339

Forkomsi FEB UGM. (2019). Revolusi Industri 4.0. In Revolusi Industri 4.0.

Gibbs, G. (1988). Learning by Doing: A guide to teaching and learning methods. In Oxford Brookes University. https://doi.org/978-1-873576-86-1

Haryanto, D. P. (2007). INOVASI PEMBELAJARAN. Perspektif Ilmu Pendidikan. https://doi.org/10.21009/pip.162.11

Hasanah, A., \& Utami, L. (2017). Pengaruh Penerapan Model Problem Based Learning Terhadap Keterampilan Proses Sains Siswa. Jurnal Pendidikan Sains (JPS).

Hmelo-Silver, C. E. (2004). Problem-based learning: What and how do students learn? Educational Psychology Review. https://doi.org/10.1023/B:EDPR.00000 34022.16470.f3

Huseno, T. (2018). Strategi Perguruan Tinggi dalam Upaya Meningkatkan Kualitas Sumberdaya Manusia Menghadapi Era Revolusi Industri 4.0. REKAMAN.

Kolb, A. Y., \& Kolb, D. A. (2005). Learning styles and learning spaces: Enhancing experiential learning in higher education. Academy of Management Learning and Education. https://doi.org/10.5465/AMLE.2005.17 268566

Kolb, D. (1984). Experiential learning: experience as the source of learning and development. Prentice Hall. https://doi.org/10.1016/B978-0-75067223-8.50017-4 
Learning, D. G. (2001). The Digital

Game-Based Learning

Revolution. Learning. https://doi.org/10.1016/j.iheduc. 2004.12.001

Learning, P. (2001). Features of ProblemBased Learning. Winter.

Made, W. (2009). Strategi Pembelajaran Inovatif Kontemporer: Suatu Tinjauan Konseptual Operasional. Jakarta: PT. Bumi Aksara.

March, J. G. (1991). Exploration and Exploitation in Organizational Learning. Organization Science. https://doi.org/10.1287/orsc.2.1.71

Michaelsen, E., \& Meidow, J. (2019). Learning. In Advances in Computer Vision and Pattern Recognition. https://doi.org/10.1007/978-3-03004040-6_13

Nakada, A., Okada, Y., Yoshihara, A., Namiki, A., \& Hiroi, N. (2017). Problem-based learning. Journal of the Medical Society of Toho University. https://doi.org/10.14994/tohoigaku:201 7-005

Noh, N. M., Merylina, H., Mustafa, A., Hamzah, M., Ismail, A., \& Abdullah, N. (2013). PENGGUNAAN INOVASI TEKNOLOGI DALAM PENGAJARAN : CABARAN GURU DALAM E- PEMBELAJARAN. PROCEEDINGS OF THE 7 TH INTERNATIONAL MALAYSIAN EDUCATIONAL TECHNOLOGY CONVENTION ( IMETC 2013 ).

Nurdiansyah, \& Fariyatul Fahyuni, E. (2016). Inovasi Model Pembelajaran. In Nizamial Learning Center.

Partnership for 21st Century Learning Skills. (2011). Framework for 21st Century Learning. P21 Framework Definitions.
Prasetyo, B., \& Trisyanti, U. (2018).

Revolusi industri 4.0 dan tantangan perubahan sosial. "Strategi Pembangunan Nasional Menghadapi Revolusi Industri 4.0."

Rusk, N. (2015). Deep learning. Nature Methods. https://doi.org/10.1038/nmeth.3707

Savery, J. R. (2012). Overview of Problembased Learning: Definitions and Distinctions. Interdisciplinary Journal of Problem-Based Learning. https://doi.org/10.7771/15415015.1002

Sulaiman, F. (2010). Students' perceptions of implementing problem-based learning in a physics course. Procedia Social and Behavioral Sciences. https://doi.org/10.1016/j.sbspro.2010.1 0.048

Sunarno, W. (2018). Makalah Utama Peran Pendidik dan Ilmuwan Sains dalam Menyongsong Revolusi ISSN : 25276670 Pembelajaran IPA di Era Revolusi Industri 4 . 0. Prosiding Seminar Nasional Pendidikan Fisika $I V$.

Suwardana, H. (2017). Revolusi Industri 4.0 Berbasis Revolusi Mental. ATI UNIK 2017, Vol . 1 No. 2 Hal 102-110. https://doi.org/http://ojs.unikkediri.ac.id/index.php/jatiunik/article/vi ew/117/0

Tuma, J. M., \& Pratt, J. M. (1982). Clinical child psychology practice and training: A survey. Vldots of Clinical Child \& Adolescent Psychology, 137(August 2012), $37-41$. http://doi.org/10.1037/a0022390, Gobry, F. (1999). \{T\}his is a title. $\{\mathrm{M}\}$ y Journal, 1, 120-130., Osment, S. E. (1980). T. A. of R. 1250-1550. ... 
and R. H. of L. M. and R. ... R. from http://scholar. google. com/scholar?hl=en\&btnG=Search \&q=i ntitle:THE+AGE+OF+REFORM+125. -1550\#2\%5Cnhttp://scholar. google. com/scholar?hl=en\&btnG=S., Caprara, G., \& Fida, R. (2008). Longitudinal analysis of the role of perceived selfefficacy for self-regulated learning in academic continuance and achievement. ... of Educational ..., 100(3), 525-534. http://doi.org/10.1037/0022-

0663.100.3.525, Shanker, S. (2003). Philosophy of science, logic and mathematics in the twentieth century. ... P. L. and N. Y. R. http://doi. org/10. 4324/978020302947., Marenbon, J. (1998). R. H. of P. I. ... P. L. and N. Y. R. http://doi. org/10. 4324/978020306227., ... Keshav, S. (2007). How to Read a Paper. Work, 37(3), 83-84. http://doi.org/10.1145/1273445.127345

8. (2004). Foundations of problembased learning. SRHE and Open University Press Imprint.

Universitas Negeri Malang. (2016). Inovasi Pendidikan di Era Big Data dan Aspek Psikologinya. Inovasi Pendidikan Di

Era Big Data Dan Aspek Psikologinya.

Wahyudin D, S. R. (2011). Inovasi

Pendidikan Dan Pembelajaran.

Kurikulum Pembelajaran. 